Research Article

\title{
Experimental Study on Stress Uniformity and Deformation Behavior of Coals with Different Length-to-Diameter Ratios under Dynamic Compression
}

\author{
Qiupeng Yuan $\mathbb{D}^{1,2}$ Guangxiang Xie, ${ }^{1,2}$ Lei Wang $\mathbb{C D}^{1,2}$ Zhenhua Jiao, $^{1}$ Peng Zou, ${ }^{1,2}$ \\ Huaiqian Liu $\mathbb{D},{ }^{3}$ and Naseer Muhammad Khan $\mathbb{D}^{4,5}$ \\ ${ }^{1}$ State Key Laboratory of Mining Response and Disaster Prevention and Control in Deep Coal Mines, \\ Anhui University of Science and Technology, Huainan 232000, Anhui, China \\ ${ }^{2}$ School of Mining Engineering, Anhui University of Science and Technology, Huainan 232000, Anhui, China \\ ${ }^{3}$ School of Energy and Mining Engineering, China University of Mining and Technology (Beijing), Beijing 100000, China \\ ${ }^{4}$ State Key Laboratory of Coal Resources and Mine Safety, China University of Mining and Technology, \\ Xuzhou 221116, Jiangsu, China \\ ${ }^{5}$ Department of Mining Engineering, Balochistan University of Information Technology Engineering and \\ Management Sciences, Quetta, Pakistan
}

Correspondence should be addressed to Lei Wang; leiwang723@126.com

Received 26 November 2020; Revised 30 December 2020; Accepted 23 March 2021; Published 13 May 2021

Academic Editor: Nur Izzi Md. Yusoff

Copyright (C) 2021 Qiupeng Yuan et al. This is an open access article distributed under the Creative Commons Attribution License, which permits unrestricted use, distribution, and reproduction in any medium, provided the original work is properly cited.

In this study, a uniaxial impact compression test was performed on coal samples with length-to-diameter $(L / D)$ ratios of $0.3,0.4$, $0.5,0.6,0.7,0.8,0.9$, and 1 using a $\Phi 50 \mathrm{~mm}$ split Hopkinson pressure bar (SHPB) test system. This study researched the stress uniformity and deformation behavior of coal samples with different $(L / D)$ ratios during dynamic compression, defined the stress equilibrium coefficient $\xi$, proposed a new method for determining whether a sample meets the stress uniformity hypothesis, and obtained the critical $(L / D)$ ratio of 0.6 and the optimal $(L / D)$ ratio of 0.3 or 0.4 for coal samples to obtain the stress equilibrium. The experimental results showed that the dynamic stress-strain curve of coal had an elastic stage, a plastic stage, and a failure stage. As the $(L / D)$ ratio increased, the proportion of the elastic stage to the prepeak curve of the samples declined progressively; with an increase in the $(L / D)$ ratio, the peak part of the curve also changed from "sharp" to "stagnated," while an increase in the plasticity led to strain softening. As the $(L / D)$ ratio of the samples increased, the average strain rate decreased approximately as a power function, and the decreasing trend was gradually reduced from $296.49 \mathrm{~s}^{-1}(L / D=0.3)$ to $102.85 \mathrm{~s}^{-1}(L / D=1)$, with a reduction of approximately $65.31 \%$. With an increase in the $L / D$ ratio, the peak strain gradually decreased exponentially. This study concluded that the SHPB test protocol design is of a certain reference value for low-density, low-strength, heterogeneous brittle materials, such as coal.

\section{Introduction}

Coal mining engineering involves various impact dynamics problems, including blasting excavation, coal wall scraping and cutting, and mining disturbances. Roof and floor fractures, fault slips, or coal pillar ruptures in coal mines may induce stress waves (dynamic loads), the propagation of which acts on coal and rock masses in the stope, causing dynamic disasters [1-6]. Studies show that the strain rate acting on coal is between 10 and $10^{3} \mathrm{~s}^{-1}$ during coal mining, storage, and transportation [7]. Hence, research on the dynamic response characteristics of coal is of great significance for coal mine disaster prevention and control and safety improvement in coal mining.

The impact dynamics of coal and rock mass are often tested with the split Hopkinson pressure bar (SHPB) system [8]. Since Kolsky [9] proposed this system, the constantly improved SHPB experimental technique has been 
extensively used in brittle materials with low fracture failure strains, such as rock and concrete $[10,11]$. The SHPB experimental technique is based on the one-dimensional (1D) stress wave hypothesis and specimen stress uniformity hypothesis. For a rod with small diameters, the 1D stress wave hypothesis is substantially true [12]; thus, uniformity hypothesis verification becomes the key to judging the accuracy of the test results. Many scholars and experts have studied the stress uniformity and stress equilibrium of specimens in SHPB. By comparing stress equilibrium factors of different waveforms, $\mathrm{Xu}$ et al. brought forward methods for improving the early-stage stress uniformity of specimens [13]. $\mathrm{Hu}$ and Song reported that the nonuniformity issue often exists in the early stage of loading and employed the elastic wave theory-based analysis to determine the loading conditions to achieve constant strain rate loading for testing brittle materials [14]. Qi et al. found that the stress equilibrium time was affected by the generalized wave impedance ratio of the specimen/pressure rod and the rise-time of the incident wave and proposed a control method to reduce the strain when rock specimens were at stress equilibrium [15]. Gong studied a variety of rocks and reported that there was a quadratic function relationship between the rock wave velocity and the maximum length of the rock sample; they also presented a method for determining the size of the rock sample [16]. Li et al. [17-22] showed that the SHPB test results were closely associated with the length-to-diameter $(L / D)$ ratio of the samples. Most of the study objects of impact dynamics of coal and rock masses at the stress equilibrium are hard rocks with a high strength and density, such as sandstone and granite [23-31], and there are few studies on soft rocks with a static strength usually less than $10 \mathrm{MPa}$ and a density less than $1.5 \mathrm{~g} / \mathrm{cm}^{3}$. It is more difficult for such soft materials to achieve stress uniformity during impact; therefore, ensuring the stress uniformity of coal before impact failure is the basis for accurate and reliable results.

Compared with rock, coal exhibits a low-density, low-strength, and more-complex internal pores, which makes it more difficult to achieve stress equilibrium. There is no research on the stress equilibrium of soft materials, such as coal, or the method for determining whether a sample meets the stress uniformity condition before failure. To this end, combining the dynamic compression test of coals with different $L / D$ ratios with the principles of the SHPB test, this paper clarified the essential characteristics of the stressstrain curve, proposed a new method for judging the sample's stress uniformity condition before sample failure, and identified the critical and optimal $L / D$ ratios that meet the stress equilibrium condition, thereby providing a reference for determining the size of the coal sample under similar circumstances.

\section{Test Protocol}

2.1. Test Equipment. Figure 1 is the SHPB test system. The present study conducted dynamic compression tests using an SHPB test system. The SHPB pilot system has a $300 \mathrm{~mm}-$ long cylindrical bullet, a $10 \mathrm{~mm} \times 10 \mathrm{~mm} \times 3 \mathrm{~mm}$ rubber sheet shaper, and incident and transmission rods made of $40 \mathrm{Cr}$ alloy steel, with a long diameter of $50 \mathrm{~mm}$, a density of $7,810 \mathrm{~kg} / \mathrm{m}^{3}$, and a longitudinal wave velocity of $5,190 \mathrm{~m} / \mathrm{s}$. A high-speed camera was used to record the crack propagation process of the sample.

2.2. Sample Preparation. In this study, large pieces of coal without dirt parting and obvious cracks were used as the base material, and the vertical coal sample surface was drilled, cut, and ground until the diameter of the samples reached $50 \mathrm{~mm}$. Considering the difficulty in processing the thin coal samples, 8 groups (each of which consisted of 3 samples) of samples with $L / D$ ratios of $0.3,0.4,0.5,0.6,0.7$, $0.8,0.9$, and 1.0 were used, the unevenness of both ends of the sample was $<0.05 \mathrm{~mm}$, and the nonparallelism of both ends was $<0.02 \mathrm{~mm}$. The physical parameters, such as the volume and density of the prepared samples, were measured. A U510 nonmetal ultrasonic detector was used to accurately determine the wave velocity of the sample. The probe was properly aligned and in close contact with the specimen through the coupling agent. At the same time, specimens with obvious damage and wave velocity deviations $>10 \%$ were excluded. Samples were marked with $D$, and each group of samples was numbered consecutively. For example, "D-0.5-2" represents the second sample from the group of dynamic loading samples with a $L / D$ ratio of 0.5 .

2.3. Test Method. To discuss the effect of the coal $L / D$ ratio on the stress equilibrium, this study used a uniform impact air pressure and determined the velocity of the bullet before collision through the laser velocimeter in front of the incident rod. To collect accurate waveform data, the incident and transmission rods were level and concentrically aligned before the test, and the empty rod was calibrated and adjusted with Vaseline as a lubricant to ensure there were substantially no reflected waves.

After testing a brass sheet, rubberized fabric, and other materials as pulse shapers, this study employed a square rubber sheet as the shaper. Figure 2 shows the classical waveform diagram of the coal SHPB test with a rubber sheet as the pulse shaper. As shown in the figure, the stress waves are smooth as a whole and exhibit no distinct dispersion effect, which conforms to the $1 \mathrm{D}$ stress wave propagation theory. The incident wave is half of a sine wave with a long rising edge, which facilitates the stress uniformity of the specimen, and the reflected and transmitted waves are similar to the incident wave in terms of the waveform.

\section{Analysis of the Results}

3.1. Essential Features of the Stress-Strain Curve. Voltage signals captured by an oscilloscope were calculated with the strain gauge method and converted into strains. The stress, strain, and strain rate of the samples were calculated using equation (1) based on the SHPB experiment theory to obtain the stress-time history curve, the strain-time history curve, and the strain rate-time history curve, thereby calculating the dynamic strength and average strain rate of the sample 


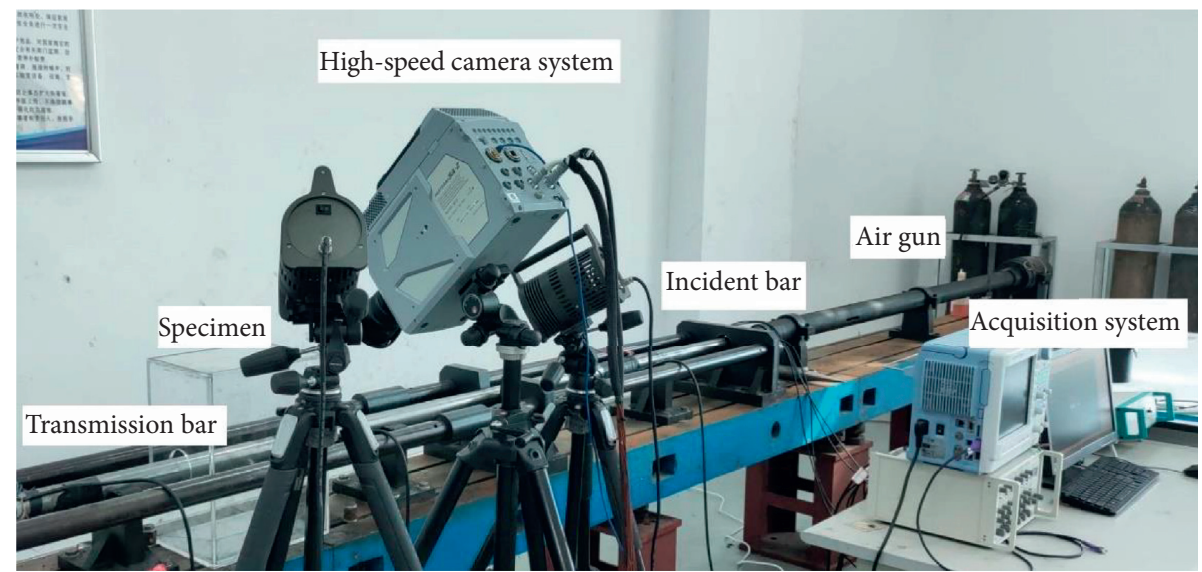

Figure 1: SHPB test system.

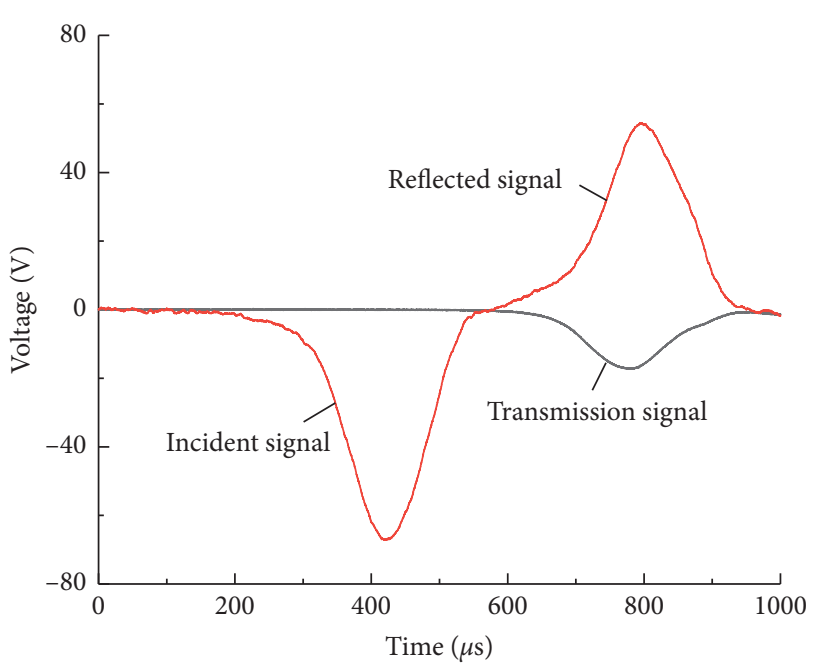

FIGURE 2: Classical waveform diagram of the coal SHPB test.

[32]. The dynamic stress-strain curve of the sample was plotted based on the stress-time history curve and the straintime history curve. The variation in the coal dynamic deformation behavior with the $L / D$ ratio is shown in Table 1 .

$$
\left\{\begin{array}{l}
\sigma(t)=\frac{E A}{A_{0}} \varepsilon_{T}(t), \\
\varepsilon(t)=-\frac{2 c_{0}}{l_{0}} \int_{0}^{t} \varepsilon_{R}(t) \mathrm{d} t, \\
\dot{\varepsilon}(t)=-\frac{2 c_{0}}{l_{0}} \varepsilon_{R}(t),
\end{array}\right.
$$

where $\varepsilon_{R}(t)$ and $\varepsilon_{T}(t)$ are the strain-in-rod corresponding to the reflected wave and transmitted wave at a time $t$ during independent transmission, respectively; $A, E$, and $c_{0}$ represent the cross-sectional area, elasticity modulus, and longitudinal wave velocity of the elastic pressure rod, respectively; furthermore, $A_{0}$ and $l_{0}$ are the cross-sectional area and original length of the sample, respectively.
Figure 3 is a typical dynamic stress-strain curve of coal with different $L / D$ ratios from an SHPB test. As shown in the figure, the dynamic stress-strain curve of coal can be divided into the following 3 stages, according to the shape, slope, and curvature of the curve. Figure 4 shows the stages of the dynamic stress-strain curve.

Elastic stage $\left(\left(\mathrm{d}^{2} \sigma / \mathrm{d} \varepsilon^{2}\right)=0, \quad(\mathrm{~d} \sigma / \mathrm{d} \varepsilon)>0\right.$, stage a in Figure 4): the stress-strain curve rises linearly at this stage. Since the dynamic loading rate is higher than the static loading rate, the sample is obviously brittle, its stress-strain curve is different from that under static loading, and it initially rises with a certain slope. At this stage, the sample load increases with the reflection and refraction of stress waves in the specimen, the internal stress of the sample is uniform, and the elastic energy accumulates in the specimen, but the stress at this time is not enough to cause damage. At this stage, the slope of the curve, i.e., the dynamic modulus of elasticity of coal, remains substantially unchanged.

Plastic stage $\left(\left(\mathrm{d}^{2} \sigma / \mathrm{d} \varepsilon^{2}\right)<0,(\mathrm{~d} \sigma / \mathrm{d} \varepsilon)>0\right.$, stage $b$ in Figure 4): the stress-strain curve is convex at this stage. At the elastic stage, the elastic energy of the sample increases continuously. When the deformation breaks through its elastic limit, the microcracks inside the sample begin to expand and irreversible plastic deformation occurs. As the slope of the curve progressively decreases, the crack growth rate gradually increases, and many new cracks develop; as a result, the stress reaches a maximum.

Failure stage $((\mathrm{d} \sigma / \mathrm{d} \varepsilon)<0$, stage $c$ in Figure 4$)$ : at this stage, the stress-strain curve descends, and the sample stress exceeds its ultimate strength. At that point, the specimen stress decreases, and the significant reduction in the bearing capacity results in a rapid deformation and failure.

3.2. Effect of the $L / D$ Ratio on the Stress-Strain Curve Characteristics. The stress-strain curves of coals with different $L / D$ ratios were substantially the same and included the three stages, but their curve characteristics were obviously different. A comparison of the curve characteristics (Figure 3 ) of coals with different $L / D$ ratios is shown in Table 2. 
TABLE 1: Variation in the coal dynamic deformation behavior with the $L / D$ ratio.

\begin{tabular}{|c|c|c|c|c|c|c|c|c|c|}
\hline \multirow[b]{2}{*}{ No. } & \multirow[b]{2}{*}{$\begin{array}{l}\text { Diameter } \times \text { length } \\
(\mathrm{mm})\end{array}$} & \multirow[b]{2}{*}{$\begin{array}{l}\text { Mass } \\
(\mathrm{g})\end{array}$} & \multirow[b]{2}{*}{$\begin{array}{l}\text { Impact rod } \\
\text { velocity } \\
\left(\mathrm{m} \cdot \mathrm{s}^{-1}\right)\end{array}$} & \multicolumn{2}{|c|}{ Average strain rate, $\dot{\varepsilon}\left(\mathrm{s}^{-1}\right)$} & \multicolumn{2}{|c|}{ Peak strain, $\varepsilon_{\mathrm{d}}$} & \multicolumn{2}{|c|}{ Peak stress, $\sigma_{d}(\mathrm{MPa})$} \\
\hline & & & & $\begin{array}{c}\text { Single } \\
\text { sample } \\
\text { value }\end{array}$ & $\begin{array}{l}\text { Arithmetic } \\
\text { average }\end{array}$ & $\begin{array}{l}\text { Single } \\
\text { sample } \\
\text { value }\end{array}$ & $\begin{array}{l}\text { Arithmetic } \\
\text { average }\end{array}$ & $\begin{array}{c}\text { Single } \\
\text { sample } \\
\text { value }\end{array}$ & $\begin{array}{l}\text { Arithmetic } \\
\text { average }\end{array}$ \\
\hline D-0.3-1 & $49.98 \times 14.53$ & 35.56 & 7.10 & 289.12 & \multirow{3}{*}{296.49} & 0.0484 & \multirow{3}{*}{0.0461} & 41.70 & \multirow{3}{*}{38.54} \\
\hline D- $0.3-2$ & $49.97 \times 15.71$ & 38.12 & 7.39 & 275.45 & & 0.0415 & & 35.40 & \\
\hline D-0.3-3 & $49.93 \times 15.13$ & 37.06 & 7.38 & 324.89 & & 0.0485 & & 38.52 & \\
\hline D-0.4-1 & $49.97 \times 19.94$ & 48.13 & 7.00 & 201.16 & \multirow{3}{*}{210.66} & 0.0280 & \multirow{3}{*}{0.0304} & 35.46 & \multirow{3}{*}{39.92} \\
\hline D-0.4-2 & $49.96 \times 20.16$ & 48.95 & 7.28 & 184.89 & & 0.0292 & & 39.41 & \\
\hline D-0.4-3 & $49.96 \times 19.89$ & 48.75 & 7.20 & 245.92 & & 0.0341 & & 44.89 & \\
\hline D- $0.5-1$ & $49.91 \times 25.31$ & 60.70 & 7.40 & 178.48 & \multirow{3}{*}{184.64} & 0.0294 & \multirow{3}{*}{0.0264} & 35.71 & \multirow{3}{*}{36.57} \\
\hline D-0.5-2 & $49.92 \times 25.21$ & 62.71 & 7.44 & 178.14 & & 0.0228 & & 39.48 & \\
\hline D- $0.5-3$ & $49.95 \times 25.18$ & 62.84 & 7.30 & 197.29 & & 0.0271 & & 34.51 & \\
\hline D-0.6-1 & $49.96 \times 30.44$ & 73.91 & 7.00 & 164.53 & \multirow{3}{*}{175.15} & 0.0234 & \multirow{3}{*}{0.0245} & 32.08 & \multirow{3}{*}{32.13} \\
\hline D-0.6-2 & $49.94 \times 30.37$ & 76.11 & 7.37 & 180.46 & & 0.0258 & & 26.35 & \\
\hline D-0.6-3 & $49.90 \times 30.28$ & 76.49 & 7.32 & 180.46 & & 0.0244 & & 38.52 & \\
\hline D-0.7-1 & $49.97 \times 35.34$ & 86.04 & 6.93 & 144.65 & \multirow{3}{*}{146.97} & 0.0208 & \multirow{3}{*}{0.0203} & 30.31 & \multirow{3}{*}{31.75} \\
\hline D-0.7-2 & $49.90 \times 35.16$ & 86.36 & 7.29 & 153.29 & & 0.0203 & & 34.06 & \\
\hline D-0.7-3 & $49.98 \times 35.24$ & 87.12 & 7.28 & 142.98 & & 0.0197 & & 30.88 & \\
\hline D-0.8-1 & $49.93 \times 40.24$ & 98.33 & 6.97 & 121.49 & \multirow{3}{*}{131.47} & 0.0155 & \multirow{3}{*}{0.0172} & 29.85 & \multirow{3}{*}{32.30} \\
\hline D-0.8-2 & $49.93 \times 40.18$ & 100.05 & 7.29 & 137.01 & & 0.0183 & & 34.25 & \\
\hline D-0.8-3 & $49.94 \times 40.14$ & 97.39 & 7.32 & 135.92 & & 0.0179 & & 32.79 & \\
\hline D-0.9-1 & $49.97 \times 45.65$ & 115.75 & 7.04 & 106.25 & \multirow{3}{*}{112.99} & 0.0122 & & 30.94 & \multirow{3}{*}{31.92} \\
\hline D-0.9-2 & $49.73 \times 45.63$ & 114.15 & 7.39 & 134.53 & & 0.0176 & 0.0141 & 32.66 & \\
\hline D-0.9-3 & $49.79 \times 45.76$ & 115.51 & 7.20 & 98.19 & & 0.0124 & & 32.15 & \\
\hline D-1-1 & $49.96 \times 50.50$ & 124.14 & 6.83 & 101.65 & \multirow{3}{*}{102.85} & 0.0147 & \multirow{3}{*}{0.0143} & 25.53 & \multirow{3}{*}{27.69} \\
\hline D-1-2 & $49.97 \times 50.56$ & 129.86 & 7.23 & 105.93 & & 0.0141 & & 34.95 & \\
\hline$D-1-3$ & $49.72 \times 50.49$ & 123.29 & 7.22 & 100.96 & & 0.0141 & & 22.60 & \\
\hline
\end{tabular}

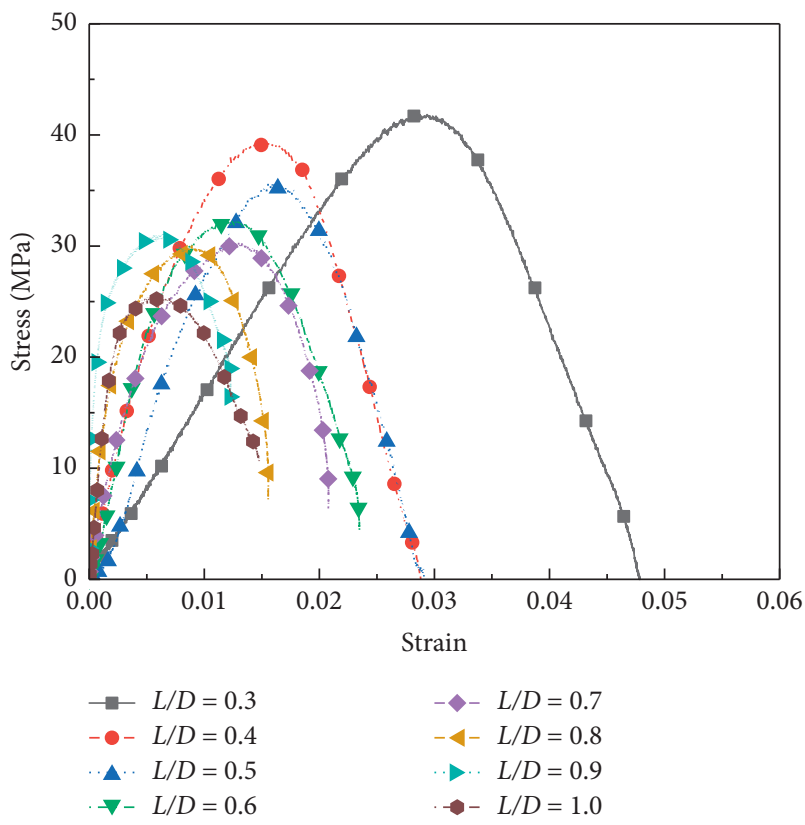

FIgURE 3: Stress-strain curve of coal with different $L / D$ ratios.

(1) The proportion of the elastic stage to the prepeak curve is shown in Table 2 . As the $L / D$ ratio increased, the proportion of the elastic stage to the prepeak curve in the sample gradually decreased from $61.5 \%$

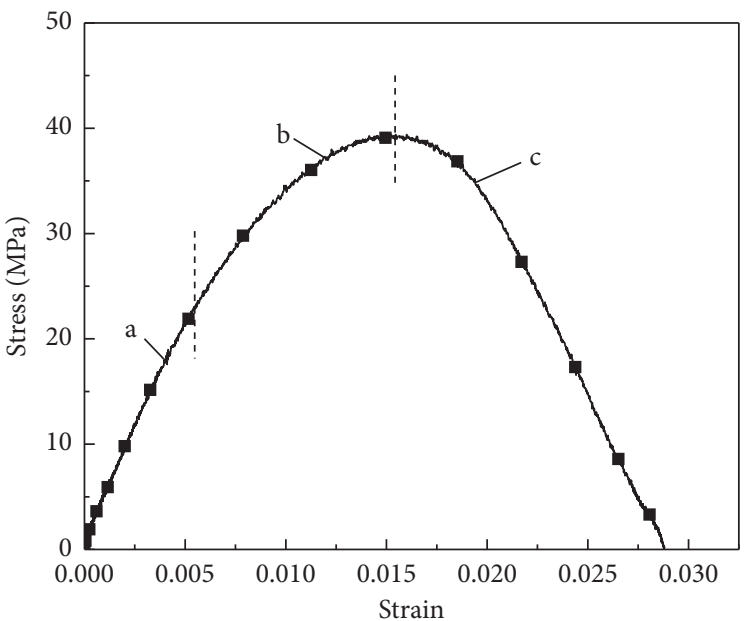

FIgURE 4: Stages of the dynamic stress-strain curve.

$(L / D=0.3)$ to $21.2 \%(L / D=1)$, with a reduction of $65.5 \%$. The postpeak strain decreased from 0.01955 to 0.00865 , which indicates that the elastic deformation of the sample with a small $L / D$ ratio was more adequate, thus it had a strong resistance to deformation.

(2) With an increase in the $L / D$ ratio, the peak part of the curve changed from "sharp" to "stagnated," and the increase in the plasticity led to strain softening. The 
TABle 2: Proportion of the elastic stage to the prepeak curve.

\begin{tabular}{lcc}
\hline No. & $\begin{array}{c}\text { Proportion of elastic stage to prepeak } \\
\text { curve (\%) }\end{array}$ & Average (\%) \\
\hline D-0.3-1 & 69.5 & 61.5 \\
D-0.3-2 & 52.9 & \\
D-0.3-3 & 62.1 & \\
\hline D-0.4-1 & 45.8 & 44.7 \\
D-0.4-2 & 40.5 & \\
D-0.4-3 & 47.7 & 32.7 \\
\hline D-0.5-1 & 43.9 & \\
D-0.5-2 & 16.4 & \\
D-0.5-3 & 37.8 & \\
\hline D-0.6-1 & 39.5 & \\
D-0.6-2 & 41.2 & \\
D-0.6-3 & 35.4 & \\
\hline D-0.7-1 & 31.6 & 21.7 \\
D-0.7-2 & 30.3 & \\
D-0.7-3 & 27.4 & \\
\hline D-0.8-1 & 19.9 & \\
D-0.8-2 & 16.1 & \\
D-0.8-3 & 24.8 & \\
\hline D-0.9-1 & 8.0 & \\
D-0.9-2 & 23.9 & \\
D-0.9-3 & 19.6 & \\
\hline D-1-1 & 14.3 & \\
D-1-2 & 29.0 & \\
D-1-3 & 20.4 & \\
\hline
\end{tabular}

reason for this change is that, after the plastic deformation of the sample, there could be a large displacement between the fragments. Because the deformation space of the long specimen is larger than that of the short specimen, the bearing capacity of the loose blocks of longer specimens decreases quickly and its strain increases rapidly.

\section{Analysis of the Dynamic Compressive Stress Uniformity}

4.1. Analysis of the Stress Equilibrium. According to the basic theory of stress wave propagation, in an SHPB impact test, the hypothesis that the internal stress of the sample reaches uniformity before failure is a prerequisite for reliable test results, i.e., the stresses on both ends of the sample should be equal. However, due to the law of stress wave transmission in the specimen, the stresses at both ends are always unequal, and it is generally believed that the stress equilibrium is reached when the stress difference between the two ends is less than $5 \%$ of the stress in the sample [32]. To quantitatively describe the effect of stress equilibrium, Li et al. [33] defined the ratio of the difference between the stresses at both ends $\sigma_{S I}-\sigma_{S T}$ to their average $\left(\left(\sigma_{S I}+\sigma_{S T}\right) / 2\right)$ as the stress equilibrium factor $\eta$ to characterize the stress equilibrium of the specimen, where $\eta$ can be obtained from the strain gauge method:

$$
\eta=\frac{2\left(\sigma_{S I}-\sigma_{S T}\right)}{\sigma_{S I}+\sigma_{S T}}=\frac{2\left(V_{S I}-V_{S T}\right)}{V_{S I}+V_{S T}}
$$

where $V_{S I}=V_{I}+V_{R}$ represents the sum of the incident voltage and reflected voltage (the $I+R$ curve in Figure 5), and $V_{S T}=V_{T}$ denotes the transmitted voltage (the $T$ curve in Figure 5). Figure 5 offers the classical stress equilibrium relationship diagrams of 8 samples with different $L / D$ ratios.

As shown in Figure 5, when $L / D=0.3$ and 0.4 , the coincidence between the $V_{S I}$ and $V_{S T}$ curves was extremely high, and $\eta$ fluctuated greatly in the initial segment of the rising edge. As the stress wave increased, $\eta$ at the rising edge and peak substantially fluctuated around 0 . The stress equilibrium can be reached at both ends of the specimen, which indicates that the stress uniformity can be reached before the specimen is destroyed. When $L / D=0.5$ and 0.6 , $\eta$ at the rising edge of the $V_{S I}$ and $V_{S T}$ curves approached 0 , but the stress equilibrium was not achieved completely. When the transmitted stress reached the peak, $\eta$ was essentially close to 0 , and the stresses in the specimen substantially reached equilibrium. When $L / D=0.7,0.8$, 0.9 , and 1 , there were excessively large time differences or stress differences between the peaks of the $V_{S I}$ and $V_{S T}$ curves, which led to a low coincidence, and $\eta$ failed to stay around 0 during the impact failure of the sample, so it was impossible for the sample to achieve stress uniformity; that is, the stresses at both ends were in a nonequilibrium state.

The stress equilibrium of other impact samples was also analyzed according to equation (2). The results showed that the samples with $L / D$ ratios of $0.3,0.4,0.5$, and 0.6 exhibited high degrees of stress equilibrium and achieved a stress uniformity before failure. For samples with $L / D$ ratios of 0.3 and 0.4 , the stress equilibrium was the best, while it was extremely difficult for samples with $L / D$ ratios of $0.7,0.8,0.9$, and 1 to achieve stress equilibrium. The analysis shows that there is a critical $L / D$ ratio for reaching stress equilibrium for samples, such as coal, and when the $L / D$ ratio is over such a critical value, it would be impossible for the sample to reach stress equilibrium during impact.

4.2. A New Method for Determining Stress Uniformity. $\eta$ offers a method for determining the stress equilibrium at both ends of the sample at a given moment. To further determine whether the stress equilibrium is reached before sample failure in an SHPB test, the $\eta s$ before the peak of the transmitted stress are subjected to a statistical analysis to define the stress equilibrium coefficient $\xi$ :

$$
\xi=\frac{n}{N} \times 100 \%,
$$

where $\xi$ is the stress equilibrium coefficient; $N$ is the number of $\eta s$ before the peak of transmitted stress in the sample; and $n$ represents the number of $\eta s$ in the sample that meets the condition of $-0.05 \leq \eta \leq 0.05$.

In the SHPB test on coal, the rising edge of the dynamic impact lasts $160-190 \mu$ s. To reduce the effect of an uneven stress of the specimen at the initial stage, $1 / 4$ th-1/3rd of the entire rise-time (approximately $50 \mu \mathrm{s}$ ) after the rising edge was selected. Considering that $\xi$ was used to determine whether the stress equilibrium was reached before the 

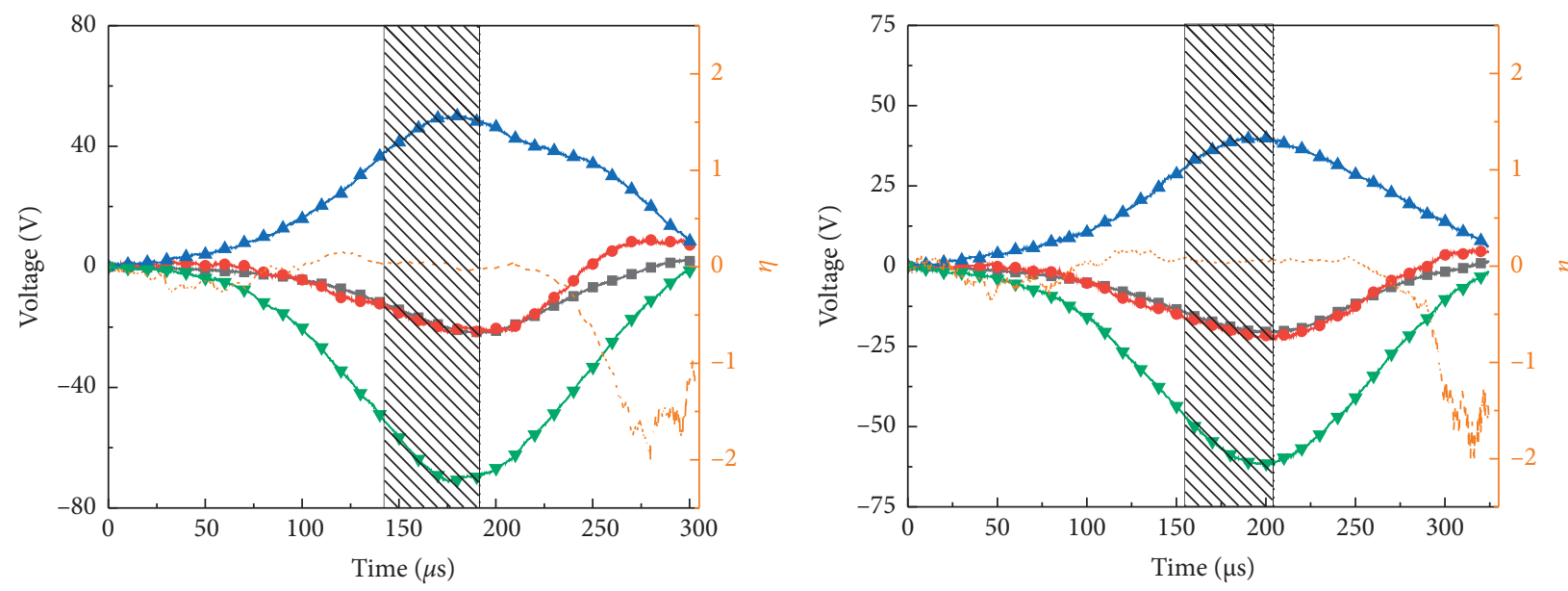

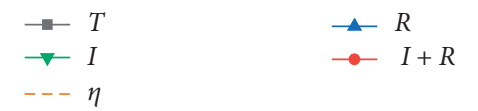

(a)

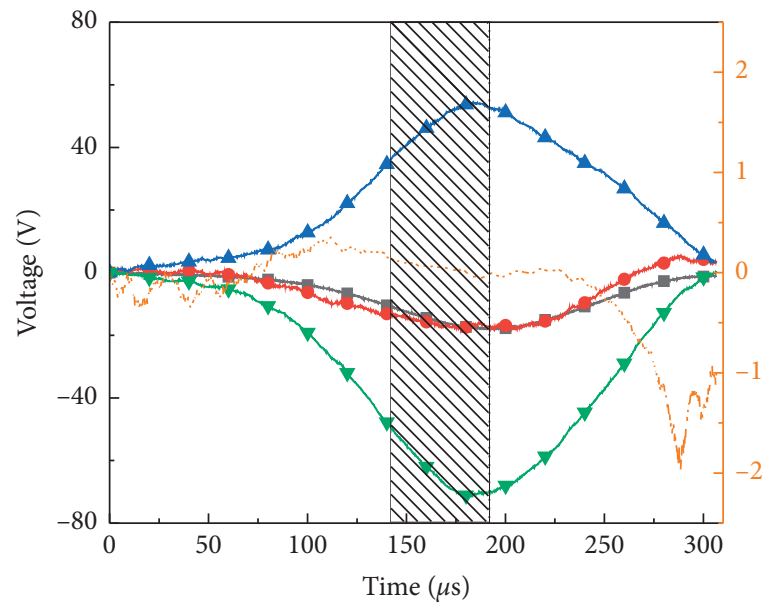

$$
\begin{aligned}
& \rightarrow T \\
& \rightarrow I \\
& --\eta
\end{aligned}
$$

$\hookrightarrow R$
$\multimap I+R$

(c)

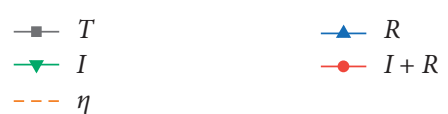

(b)

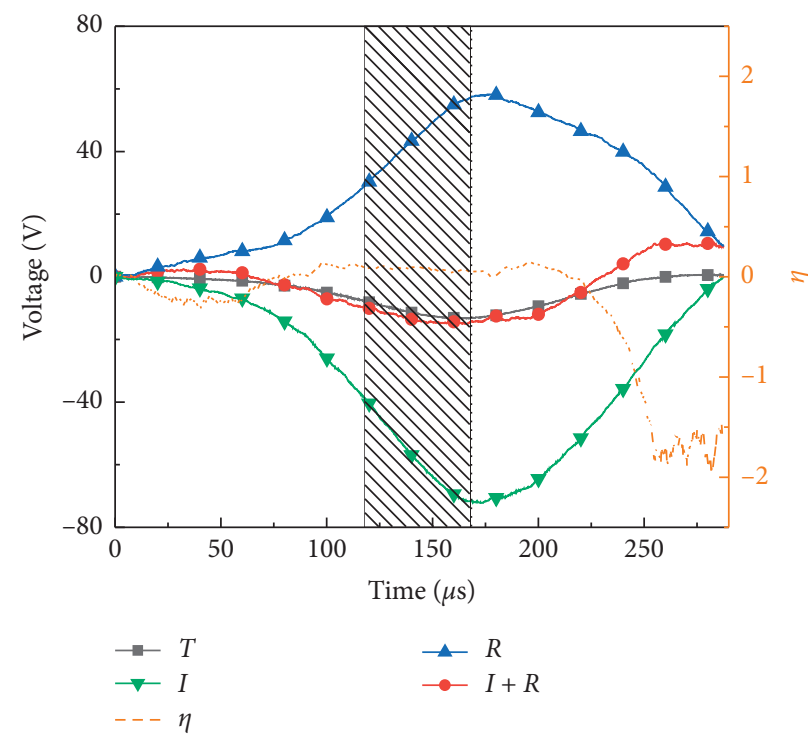

(d)

FIgURE 5: Continued. 


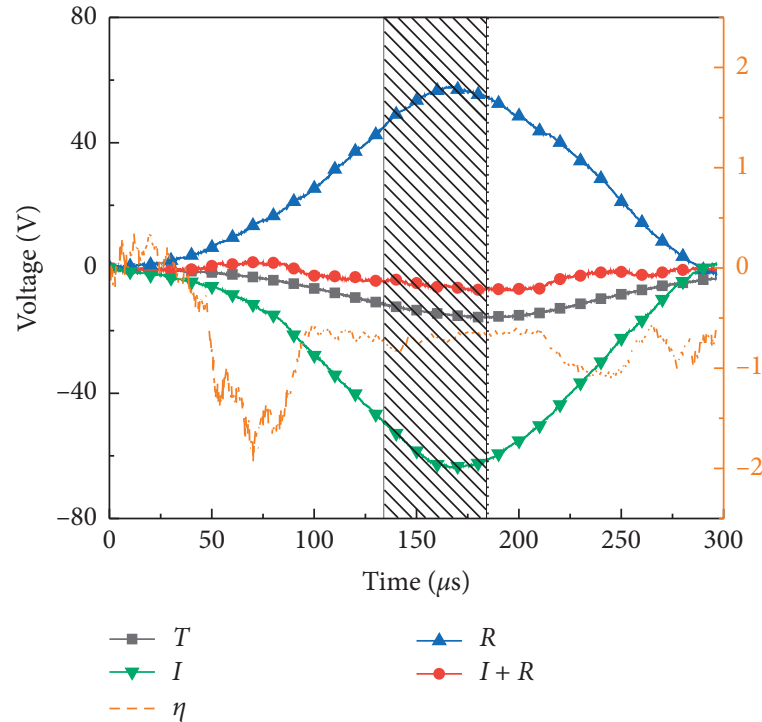

(e)

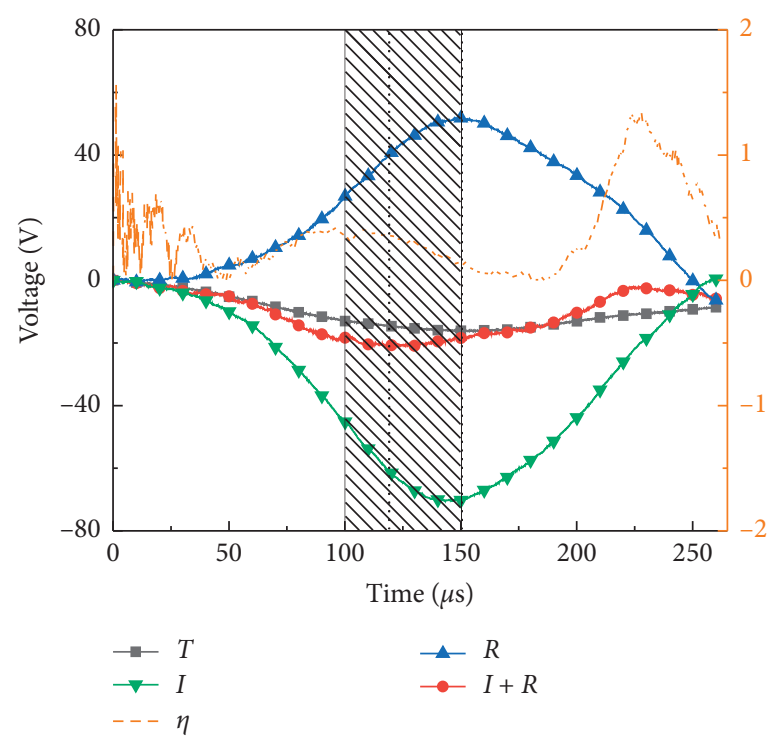

(g)

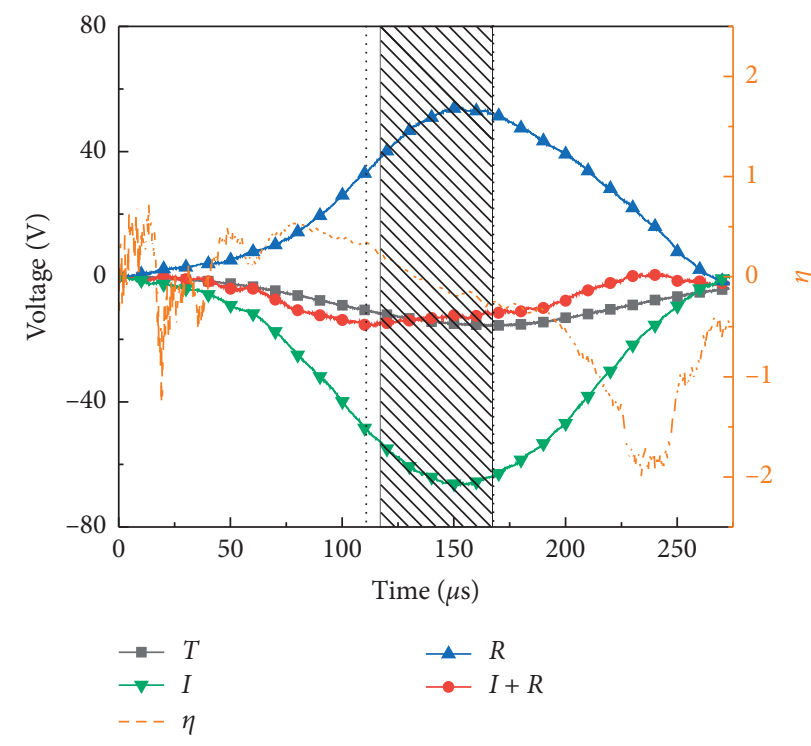

(f)

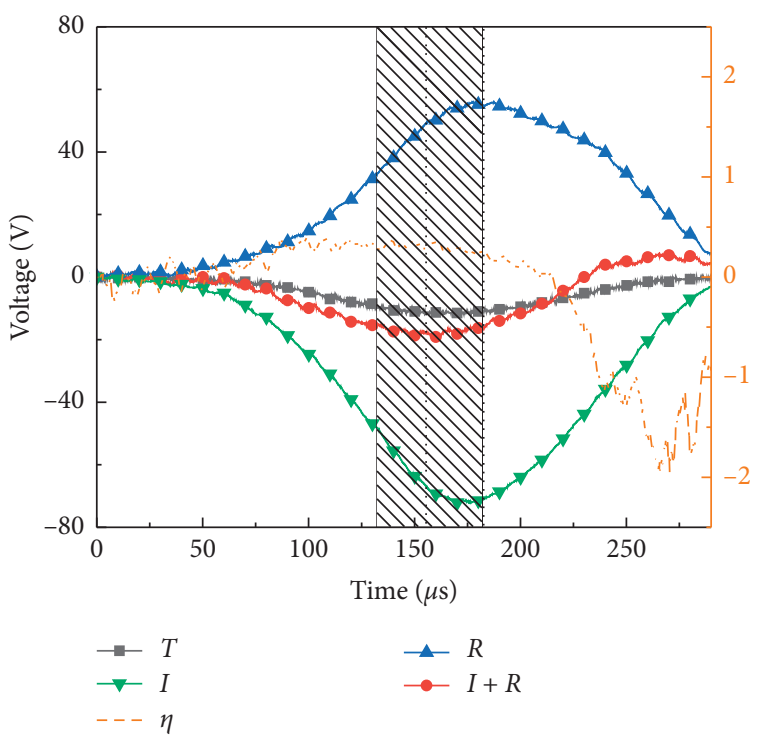

(h)

Figure 5: Stress equilibrium of samples with different $L / D$ ratios. (a) $L / D=0.3$. (b) $L / D=0.4$. (c) $L / D=0.5$. (d) $L / D=0.6$. (e) $L / D=0.7$. (f) $L / D=0.8$. (g) $L / D=0.9$. (h) $L / D=1$.

sample failure, the transmitted stress peak was selected as the target, and the $\eta s$ of the first $50 \mathrm{~s}$ were selected as the samples (as shown in the shaded part in Figure 5). $\xi$ was calculated by this method, and the average $\xi$ values corresponding to samples with $L / D$ ratios of $0.3,0.4,0.5$, and 0.6 were $87.3 \%$, $64.6 \%, 28.7 \%$, and $16.4 \%$, respectively, while the corresponding minimum $\xi$ values were $80 \%, 46.6 \%, 20.2 \%$, and $4.6 \%$, respectively. The $\xi$ of specimens with other $L / D$ ratios was 0 , that is, the stress equilibrium cannot be met before failure in these specimens.

The results showed that, from the perspective of stress equilibrium, the optimal $L / D$ ratio of the coal sample should be 0.3 or 0.4 , and when the $L / D$ was greater than the critical $L / D$ ratio of 0.6 , it was impossible for the specimen to reach the stress equilibrium.

\section{Effect of the $L / D$ Ratio on the Dynamic Deformation Behavior of Coals}

The data processing was based on the principle of the SHPB test, and samples that cannot reach stress equilibrium had no analytical significance. Therefore, the following paragraphs focus on the analysis of the dynamic deformation behavior of coal. The variation trends of the average strain rate $\dot{\varepsilon}$, peak strain, peak stress $\sigma_{d}$, and dynamic modulus of elasticity $E_{\mathrm{d}}$ with the $L / D$ ratio were obtained based on stress-strain curves of coals with different $L / D$ ratios (Table 1 ).

5.1. Effect of the $L / D$ Ratio on the Average Strain Rate $\dot{\varepsilon}$. Average strain rate refers to the strain rate corresponding to the peak stress of the sample. The strain rate is the amount of 


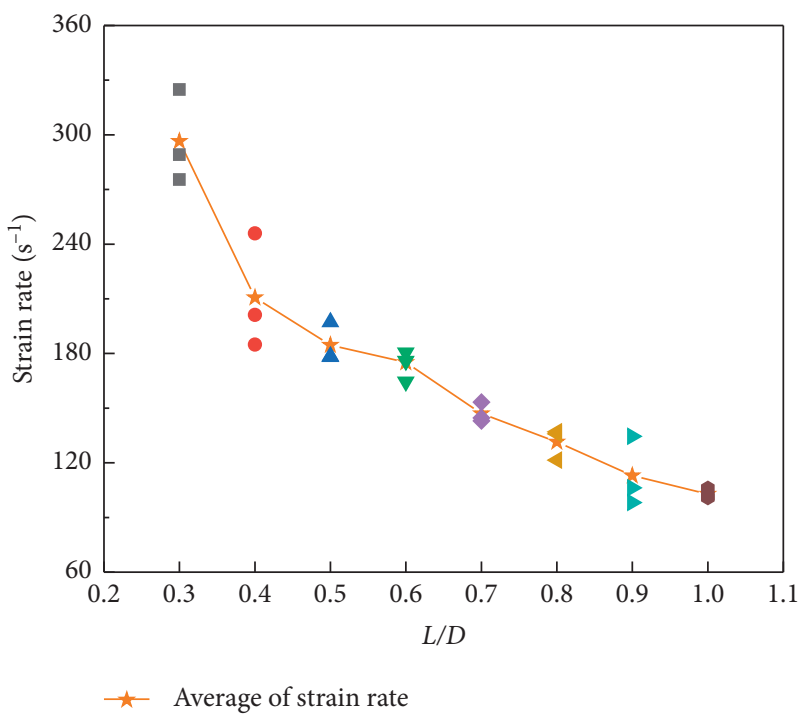

FIgURE 6: Changing curve of the average strain rate with the $L / D$ ratio.

strain in the sample per unit time, which can characterize the loaded condition of the sample. Figure 6 shows the changing curve of the average strain rate with the $L / D$ ratio.

The samples were from the same parent rock, but due to the heterogeneity of coal, there were still some differences among the samples. As a result, there was a certain degree of dispersion in the average strain rate of coal with the same $L / D$ ratio. However, overall, as the $L / D$ ratio increased, the average strain rate gradually decreased from $296.49 \mathrm{~s}^{-1}$ $(L / D=0.3)$ to $102.85 \mathrm{~s}^{-1}(L / D=1)$, with a reduction of $65.31 \%$.

Based on the various characteristics of the average strain rate with $L / D$, the functional relationship between them was obtained by fitting the curve:

$$
\begin{aligned}
\dot{\varepsilon} & =24.872+83.431(L / D)^{-0.961,}, \\
R^{2} & =0.979 .
\end{aligned}
$$

As shown in equation (4), as the $L / D$ ratio increased, the average strain rate of the specimen decreased in an approximate power function, and the downward trend progressively slowed down. Figure 7 shows photos of the crack growth morphology of coal samples with different $L / D$ ratios $(0.3-1)$ using a high-speed camera. Combining Figure 7 with photos of the impact-induced failure of samples by a high-speed camera, the analysis showed that as the $L / D$ ratio increased, fewer cracks were generated, and fewer cracks were crosslinked. For short specimens, under the end friction, the radial deformation is small, the stress in the middle of the specimen is concentrated and rises rapidly, the deformation occurs quickly, and the cracks of the specimen develop obviously, which is finally reflected as a high strain rate and failure. However, for long specimens, the end friction is weakened, the stress concentration in the middle of the specimen also decreases correspondingly, the increase in stress slows down, and the radial deformation increases, which is finally reflected as the relatively low strain rate and splitting failure.
5.2. Effect of the L/D Ratio on the Peak Strain. Peak strain is not only an important parameter that characterizes the degree of sample deformation but is also one of the essential mechanical parameters of coal. The changing curve of the peak strain with the $L / D$ ratio is shown in Figure 8.

As shown in Figure 8, with an increase in the $L / D$ ratio, the peak strain of coal gradually decreased. The entire changing process can be roughly divided into 2 stages as follows: (1) when the $L / D$ ratio increased from 0.3 to 0.6 , the peak strain decreased sharply from 0.0461 to 0.0251 , with a reduction of $45.55 \%$; (2) when the $L / D$ ratio increased from 0.7 to 1 , the peak strain decreased at a lower rate from 0.0203 to 0.0143 , with a reduction of $29.56 \%$. Based on this variation feature, an exponential function was used to fit the curve to obtain the functional relationship between the peak strain and the $L / D$ ratio of coal:

$$
\begin{aligned}
\mathcal{E} & =0.0132+0.113 \times 0.01417^{(L / D)}, \\
R^{2} & =0.969 .
\end{aligned}
$$

According to equation (5), as the $L / D$ ratio increased, the peak strain of coal gradually decreased exponentially. Combined with the analysis of the stress-strain curves of coals with different $L / D$ ratios (Figure 3 ), the results showed that as the $L / D$ ratio of the specimen increased, the relative contact between the broken fragments decreased, the relative displacement increased, and obvious plastic deformation occurred, which is demonstrated by an increase in the proportion of the plastic stage in the stress-strain curve before the peak. As a result, the strength and deformability of the sample decreased, which causes the ultimate deformation to decrease. Macroscopically, this is reflected by an increase in the coal fragmentation with an increase in the $L / D$ ratio. Figure 9 shows the failure modes of samples with different $L / D$ ratios. 


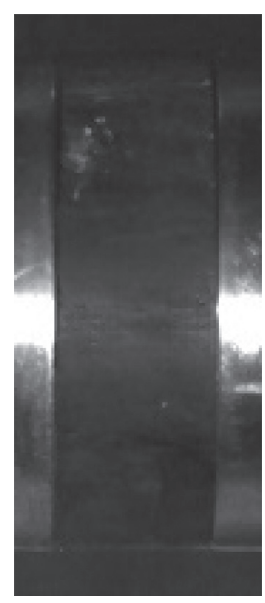

(a)

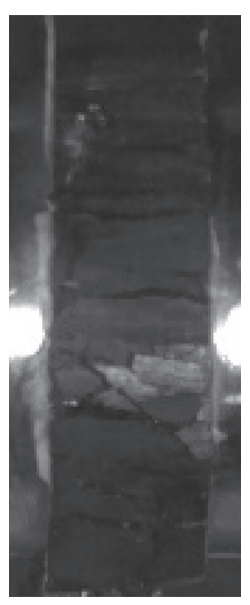

(d)

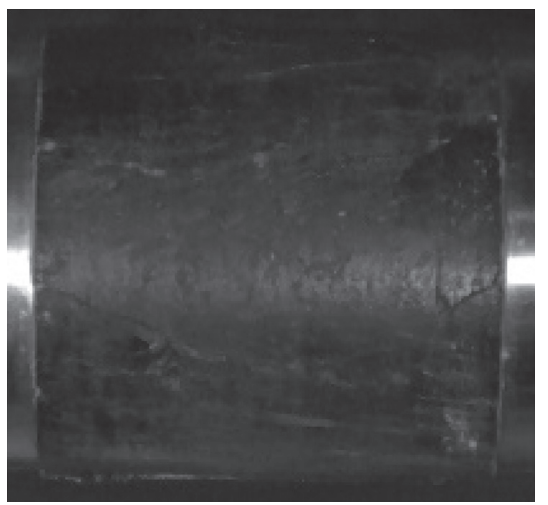

(

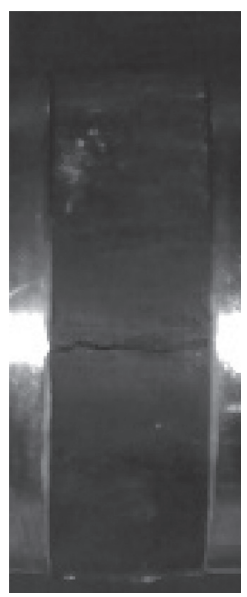

(b)

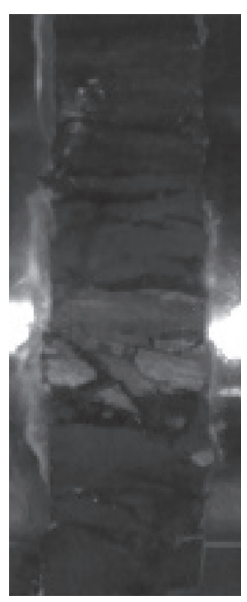

(e)

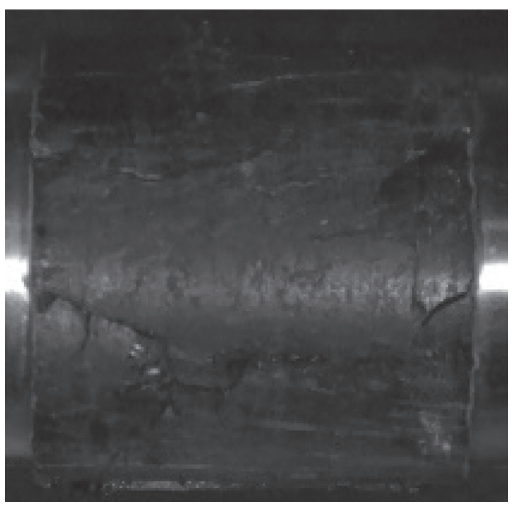

(h)

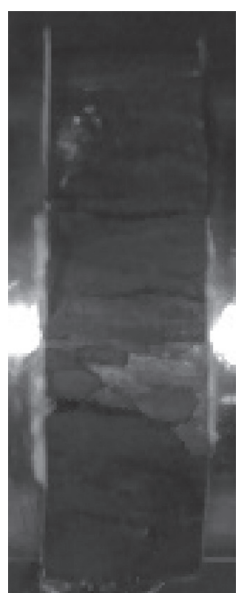

(c)

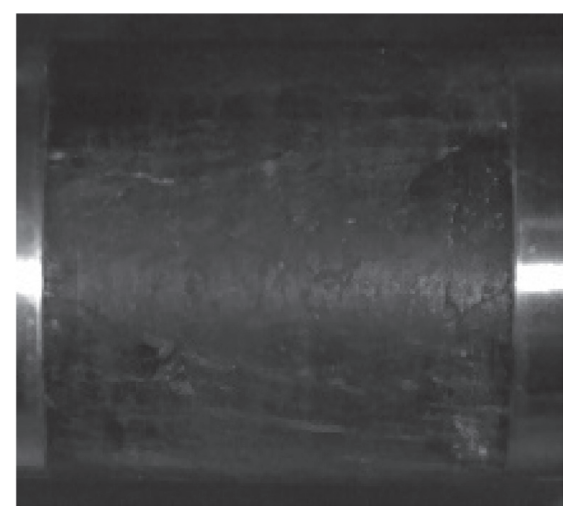

(f)

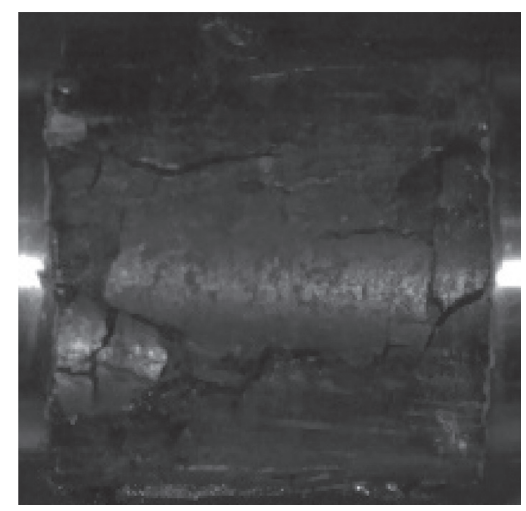

(i)

Figure 7: Photos of the failure process of two groups of coal samples with different $L / D$ ratios by a high-speed camera. (a) Sample D-0.3-3 before loading. (b) Axial split crack propagation. (c) Secondary crack propagation. (d) Crack cross-linking. (e) Sample failure. (f) Sample D1-3 before loading. (g) Cracks development due to compression and expansion. (h) Main crack propagation. (i) Crack cross-linking results in specimen rupture.

5.3. Effect of the L/D Ratio on the Peak Stress $\sigma_{d}$ and the Dynamic Modulus of Elasticity $E_{d}$. Peak stress is the dynamic compressive strength of coal and the measure of coal's ultimate bearing capacity. The dynamic modulus of elasticity can characterize the resistance of coal to deformation at a high strain rate. Figure 10 shows the peak stresses and dynamic modulus of elasticity of coal samples with different $L / D$ ratios. The analysis in Section 3.2 shows that when the $L / D$ ratio exceeded 0.7 , it was impossible for the samples to reach stress equilibrium and meet the hypothesis of stress uniformity, which is represented by the dotted line in Figure 10. The samples exhibited a certain degree of 


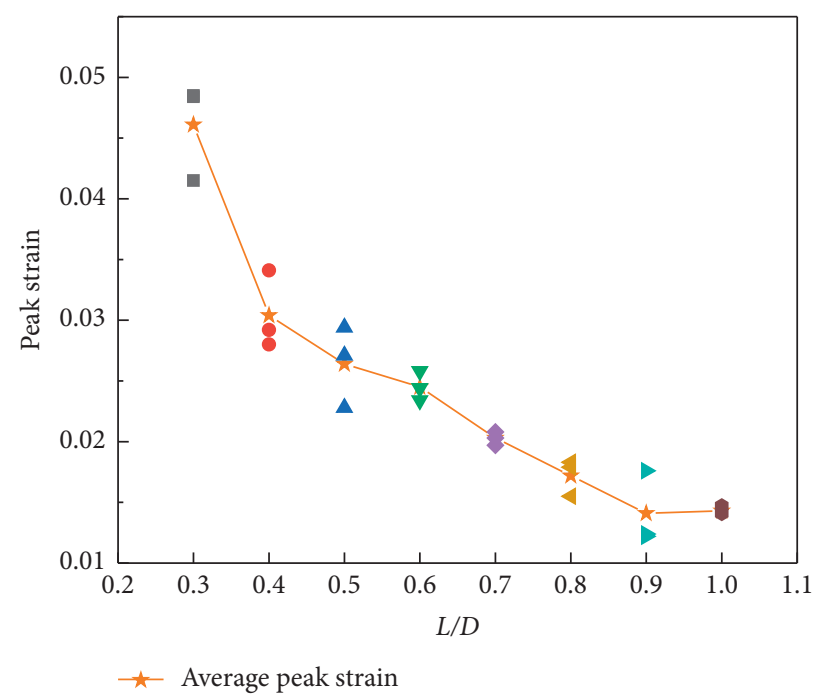

FIGURE 8: Changing curve of the peak strain with the $L / D$ ratio.
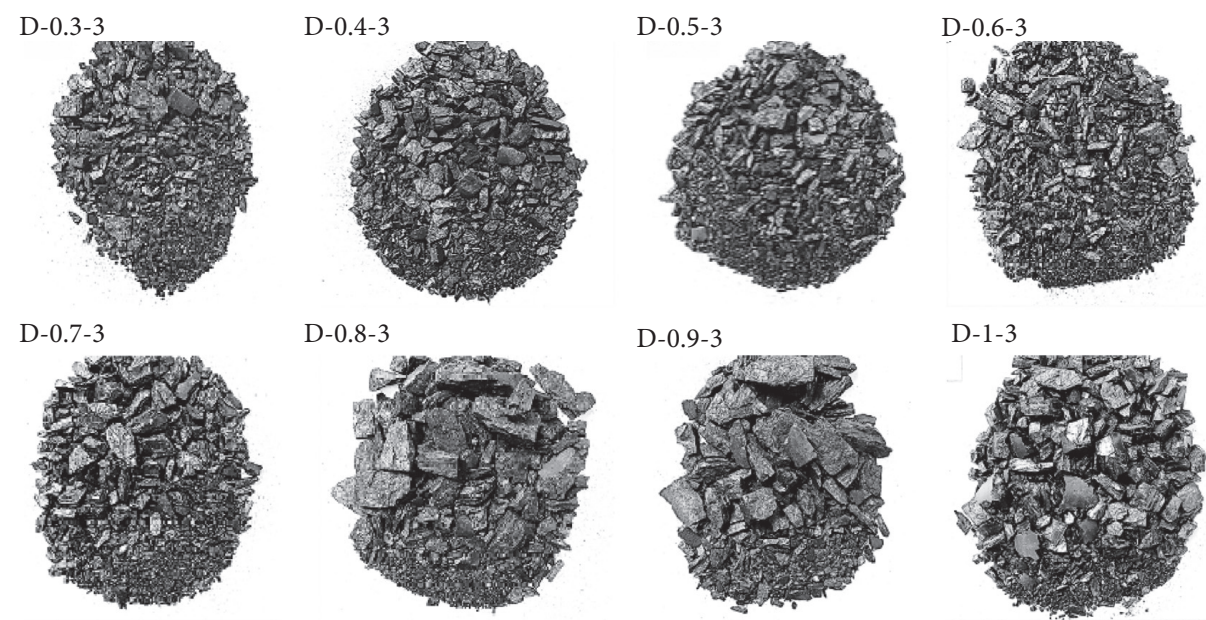

Figure 9: Failure modes of samples with different $L / D$ ratios.

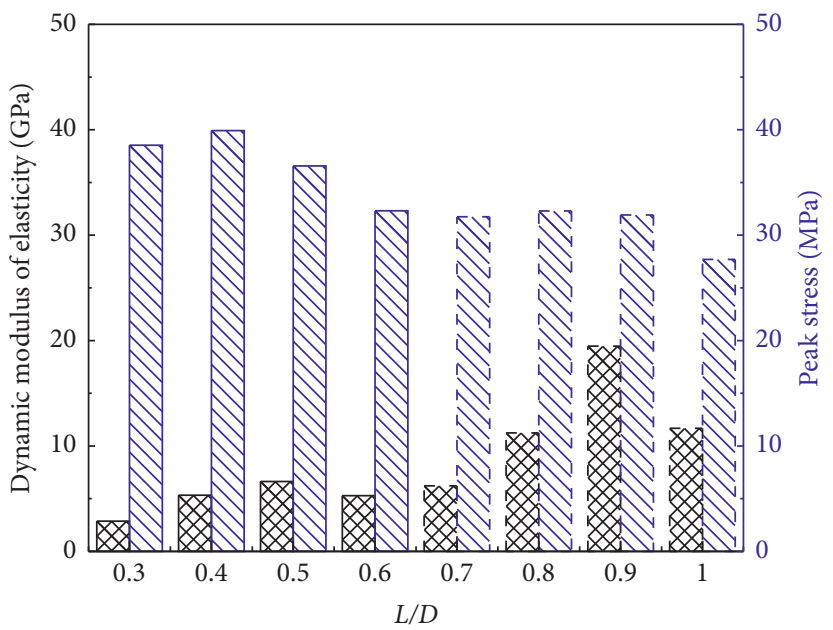

Dynamic modulus of elasticity MIV MII Peak stress

Figure 10: Dynamic modulus of elasticity and the peak stress of coal samples with different $L / D$ ratios. 
dispersion, but the overall peak stress of the coal gradually decreased, and the dynamic modulus of elasticity progressively increased with an increase in the $L / D$ ratio.

\section{Conclusion}

(1) At high strain rates, the stress-strain curve of coal was roughly divided into the elastic stage, plastic stage, and failure stage. As the $L / D$ ratio increased, the proportion of the sample's elastic stage to the prepeak curve gradually decreased from $61.5 \%$ $(L / D=0.3)$ to $21.2 \%(L / D=1)$, with a reduction of $65.5 \%$. As the strain in the postpeak section decreased from 0.01955 to 0.00865 , the peak part of the curve changed from "sharp" to "stagnated," while the increase in plasticity led to strain softening.

(2) Before the rock sample failure in the SHPB test, it was very important to ensure a uniform upward axial stress. Based on the principle of the SHPB test, a new method using $\xi$ to determine the sample stress equilibrium was proposed, and the critical $L / D$ ratio for the coal sample to meet the stress equilibrium was determined to be 0.6 , while the optimal $L / D$ ratio was found to be 0.3 or 0.4 .

(3) As the $L / D$ ratio of the sample increased, the average strain rate decreased in an approximate power function, and the downward trend slowed down; that is, the average strain rate decreased from $296.49 \mathrm{~s}^{-1}$ $(L / D=0.3)$ to $102.85 \mathrm{~s}^{-1}(L / D=1)$, with a reduction of $65.31 \%$.

(4) As the $L / D$ ratio of the sample increased, the peak strain gradually decreased exponentially. When the $L / D$ ratio increased from 0.3 to 0.6 , the peak strain decreased sharply from 0.0461 to 0.0251 , with a reduction of $45.55 \%$. When the $L / D$ ratio increased from 0.7 to 1 , the peak strain decreased at a lower rate from 0.0203 to 0.0143 , with a reduction of $29.56 \%$.

\section{Data Availability}

The data used to support the findings of this study are available from the corresponding author upon request. All the experimental data have been included in this article.

\section{Conflicts of Interest}

The authors declare that they have no conflicts of interest.

\section{References}

[1] J. Feng, Study on the Mechanism of Stress Wave and its Influence on Rock Burst, China University of Mining and Technology, Xuzhou, China, 2016.

[2] J. Feng, "Source model of compression-shear fracture of coal body and far-field vibration characteristics," Journal of China University of Mining and Technology, vol. 45, no. 3, pp. 483-489, 2016.

[3] H. Jiang, "Mechanism of dynamic and static combined load inducing rock burst in thin coal seam," Journal of China Coal Society, vol. 39, no. 11, pp. 2177-2182, 2014.
[4] S. Liu, "Under static loading stress wave propagation mechanism and energy dissipation in compound coal-rock," Journal of China Coal Society, vol. 39, no. S1, pp. 15-22, 2014.

[5] G. Dong, X. Liang, and Q. Wang, "A new method for predicting coal and gas outbursts," Shock and Vibration, vol. 2020, Article ID 8867476, 10 pages, 2020.

[6] S. Liu, J. Bai, X. Wang, B. Wu, and W. Wu, "Mechanisms of floor heave in roadways adjacent to a goaf caused by the fracturing of a competent roof and controlling technology," Shock and Vibration, vol. 2020, Article ID 5632943, 17 pages, 2020.

[7] R. Shan, R. Cheng, and W. Gao, "Study on dynamic constitutive model of anthracite of Yunjialing coal mine," Chinese Journal of Rock Mechanics and Engineering, vol. 25, no. 11, pp. 2258-2263, 2006.

[8] K. Xia and C. Zhou, "Review of testing methods for dynamic rock mechanical properties," Engineering Blasting, vol. 20, no. 2, pp. 43-53, 2014.

[9] H. Kolsky, "An investigation of the mechanical properties of materials at very high rates of loading," Proceedings of the Physical Society. Section B, vol. 62, no. 11, 1949.

[10] B. Wang and X. Li, "Mesomechanics analysis of static compressive strength and dynamic compressive strength of water-saturated rock under uniaxial load," Explosion and Shock Waves, vol. 32, no. 4, pp. 423-431, 2012.

[11] B. Su and Q. Wang, "Experimental study of dynamic mechanical properties for Quasi-brittle materials using the split Hopkinson pressure bar," Rock and Soil Mechanics, vol. 24, no. S2, pp. 580-584, 2003.

[12] X. Li, "Study on the mechanical properties of rock under the combination of dynamic and static loadings," Chinese Journal of Rock Mechanics and Engineering, vol. 27, no. 7, pp. 13871395, 2008.

[13] M. Xu, R. Zhang, and G. Zhang, "Analysis of early stage specimen stress equilibrium in SHPB experiment," Explosion and Shock Waves, vol. 23, no. 3, pp. 235-240, 2003.

[14] L. Song and S. Hu, "Stress uniformity and constant strain rate in SHPB test," Explosion and Shock Waves, vol. 25, no. 3, pp. 207-216, 2005.

[15] P. Qi, Q. Ma, and Y. Pu, "Stress equilibrium in rock specimen during the loading process of SHPB experiment," Explosion and Shock Waves, vol. 33, no. 6, pp. 655-661, 2013.

[16] F. Gong, "Reference method for determining sample size in SHPB tests of rock materials," Journal of Vibration and Shock, vol. 32, no. 17, pp. 24-28, 2013.

[17] P. Qi, Q. Ma, and Y. Pu, "Prediction for stress equilibrium time in rock SHPB test," Journal of Vibration and Shock, vol. 32, no. 12, pp. 55-60, 2013.

[18] H. Zhao, P. Qi, and H. Su, "Study on dynamic compression SHPB test of limestone with different length diameter ratios," Coal Science and Technology, vol. 46, no. 8, pp. 38-43, 2018.

[19] D. Li, "On the effect of length to diameter ratio of rock specimen subjected to dynamic and static compression," Journal of Experimental Mechanics, vol. 33, no. 1, pp. 93-100, 2018.

[20] S. Liang, "Study ON the determination OF specimen size IN SHPB experiments OF rock materials," Engineering Blasting, vol. 21, no. 5, pp. 1-5, 2015.

[21] J. Du, Study on Dynamic Characteristics of Rock Impact under Different Length Diameter Ratios, Central South University, Changsha, China, 2011.

[22] F. Gao, "Research on rock parastatic and dynamic impact test and size effect," Coal Science and Technology, vol. 37, no. 4, pp. 19-22+68, 2009. 
[23] T. H. Lv, X. W. Chen, Y. J. Deng, and G. Chen, "Further numerical investigation on concrete dynamic behaviors with considering stress non-equilibrium in SHPB test based on the waveform features," Acta Mechanica Sinica, vol. 36, no. 4, pp. 873-886, 2020.

[24] S. Pang, W. Tao, Y. Liang, Y. Liu, and S. Huan, "A modified method of pulse-shaper technique applied in SHPB," Composites Part B: Engineering, vol. 165, pp. 215-221, 2019.

[25] M. Hassan and K. Wille, "Experimental impact analysis on ultra-high performance concrete (UHPC) for achieving stress equilibrium (SE) and constant strain rate (CSR) in Split Hopkinson pressure bar (SHPB) using pulse shaping technique," Construction and Building Materials, vol. 144, pp. 747-757, 2017.

[26] T. Chakraborty, S. Mishra, J. Loukus, B. Halonen, and B. Bekkala, "Characterization of three Himalayan rocks using a split Hopkinson pressure bar," International Journal Of Rock Mechanics And Mining Sciences, vol. 85, pp. 112-118, 2016.

[27] J.-Z. Liu, J.-Y. Xu, X.-C. Lv, D.-H. Zhao, and B.-L. Leng, "Experimental study on dynamic mechanical properties of amphibolites, sericite-quartz schist and sandstone under impact loadings," International Journal of Nonlinear Sciences and Numerical Simulation, vol. 13, no. 2, pp. 209-217, 2012.

[28] G. Zhang, H. Jia, and S. Wu, "Study on dynamic mechanical properties and damage evolution model of siltstone," Shock and Vibration, vol. 2019, Article ID 5174579, 10 pages, 2019.

[29] P. Yuan, N.-N. Wei, and Q.-Y. Ma, "Effect of nonparallel end face on energy dissipation analyses of rocklike materials based on SHPB tests," Shock and Vibration, vol. 2019, Article ID 2040947, 11 pages, 2019.

[30] N. Wu, Z. Zhu, Y. Zhou, and S. Gao, "A comparative study on rock properties in splitting and compressive dynamic tests," Shock and Vibration, vol. 2018, Article ID 2861537, 12 pages, 2018.

[31] C. Li, C. Wang, B. Xie, X. Sun, and X. Xu, "Study on low-frequency TEM effect of coal during dynamic rupture," Shock and Vibration, vol. 2015, Article ID 189569, 8 pages, 2015.

[32] F. Lu, Hopkinson Bar Techniques, Science Publishing House, Beijing, China, 2013.

[33] X. Li, Y. Zou, and Z. Zhou, "Numerical simulation of the rock SHPB test with a special shape striker based on the discrete element method," Rock Mechanics and Rock Engineering, vol. 47, no. 5, 2014. 